\title{
Lind and scurvy: 1747 to 1795
}

\author{
U Tröhler
}

J R Soc Med 2005;98:519-522

Lind's Treatise of the Scurvy ${ }^{1}$ is a good illustration of the basis for mid-18th century judgement and decision-making in at least two respects: it quotes the contributions of others at length, and its therapeutic recommendations had little impact. $^{2,3}$ Lind dedicated his book to Lord Anson because an account of Anson's circumnavigation published in 1748 had prompted Lind's interest in scurvy: at least 380 out of a crew of 510 on one of Anson's ships had died of the disease. When Lind began to read the literature on scurvy, he realized that the only existing descriptions of the disease were by lay seamen and doctors who had never been to sea. 'No physician conversant with this disease at sea had undertaken to throw light upon the subject,' and Lind felt that this was one of the reasons why there was so much confusion about the diagnosis, prevention and cure of the disease. As Lind wrote bluntly: 'Indeed, before the subject could be set in clear and proper light, it was necessary to remove a great deal of rubbish'1 (p. viii).

There is no direct evidence that, in using these words, Lind was paraphrasing the empiricist philosopher-physician John Locke, who had represented himself as 'an underlabourer in clearing the ground a little, and removing some of the rubbish that lies in the way to knowledge'. But Lind certainly wrote in the spirit of Locke. Locke's 'masterbuilders' were his friends Boyle, Sydenham, Huygens and Newton, all of whom worked by observation and generation of 'facts', the very method Lind proposed for advancing an understanding of scurvy. Lind's Treatise stressed that his work was to be founded 'upon attested facts and observations, without suffering the illusions of theory to influence and pervert the judgement' ${ }^{1}$ (p. xii).

What were Lind's facts? First, he had had direct experience of scurvy since he first went to sea in the late 1730s. His longest cruise in the Channel Fleet was made during the War of the Austrian Succession aboard a fourth class ship named the Salisbury. During a 10 -week absence from shore, 80 out of 350 sailors were struck down by scurvy, and Lind's prospective controlled experiment - in which he compared the relative merits of six treatments then in use for treating the disease in 12 patients - began on board on 20 May 1747.

Institut fur Geschichte der Medizin, Stefan Meier Str 26, D-79104 Freiburg i. Br, Germany

E-mail: ulrich.troehler@igm.uni-freiburg.de
Lind subsequently added to his first hand experience in two ways: (1) he searched for, abstracted and evaluated previous reports of the disease; and (2) he drew on accounts sent to him by members of the Society of Naval Surgeons. In other words, he conducted a systematic review of what had been written on the topic by others. ${ }^{4}$

Lind judged his relatively small number of observations on 12 patients, reported in some detail, as convincing, particularly because the differences shown were so dramatic. In fact he 'confirmed' them by selected observations on other patients, but these were not as reliable as his experimental results, nor were they quantitative. In these, as well as in other experiments designed in advance, it was the quality of basic observations rather than their quantity that was important for Lind. Careful observation of a single case could even be decisive; for instance, Lind said that that he had never had a great opinion of the elixir of vitriol because he had witnessed a patient contracting scurvy to whom he had prescribed it as a 'reconstituent', that is, 'while under a course of medicine recommended for its prevention'1 (p. 196). Similarly, postulated treatments for scurvy had not only been debunked by Lind's experiment, but were 'contradicted by the daily experience of seamen, [and] by the journals of our sea-hospitals ... When claiming this, he seems to have such evidence in mind, although he did not quote it explicitly.

Lind's therapeutic findings made little impact on medical opinion in Britain: indeed, the year after their publication the Navy's Sick and Hurt Board rejected a proposal to provide sailors with supplies of fruit juice. In fact, aware of the storage problems for adequate amounts of fresh fruit or fruit-juice during long cruises, Lind recommended that a condensate (called 'rob') should be prepared by evaporating a dilution of fresh fruit juice in nearly boiling water over several hours. Unfortunately, as we now know, heat destroys much of the ascorbic acid in fresh juice, and it is unsurprising that subsequent observers were unable to detect any beneficial effect of the condensate.

In hindsight the story of how Lind's work was received, entailing a lag of 42 years between his clearly described and experimentally 'proven' treatment and its actual introduction by the relevant authorities, seemed to some 'one of the 
most foolish episodes in the whole history of medical science and practice'. However, the Navy Sick and Hurt Board did not, during the first 30 years, act unreasonably when one considers that Lind's was only one of a great number of treatises on the subject (see Lind's own Bibliotheca Scorbutica, an appendix to the first edition of his work); the Board was inundated with suggestions concerning scurvy; lemon juice was by no means a new cure (a fact of which Lind was perfectly aware); and not least because, together with his 'rob', he also recommended a list of vegetables for preventing scurvy which, on the basis of modern analyses, were unlikely to have been effective. Lind's recommendations thus sometimes ignored his declared rejection of unwarranted speculation and his professed reliance on carefully observed facts.

It is worth noting in addition that Lind's experiment had not been based on pathophysiological theory, but rather 'controlled empiricism': He gave no reason for the choice of his possible treatments. His trial succeeded because one of the remedies contained Vitamin C. He knew how to perform a comparative experiment, well controlled for time and environment, but perhaps less well, which experiment he should do. Had it been based on theory, his work might have been more likely to receive credit with the medical establishment, and Lind may have been seeking such credit when he developed a theory of scurvy, accompanied by excuses for being speculative $^{1}$ (p. 272-310)!

It seems historically relevant to recognize that Lind was successful in promoting comparative clinical trials quickly, possibly even within the Navy Sick and Hurt Board, whose lethargy has often been criticized. Besides the further trials with antiscorbutics mentioned below, the Board later also ordered trials of drugs against 'fevers' (see [www.jameslindlibrary.org/trial_records/17th_18th_Century/ lind_1763/lind_1763_commentary.html]). This was a new development and an application of the much-praised observational medicine. But, as a naval surgeon, Lind's status was lower than, say, that of an Oxonian scholar with an FRCP, pronouncing with authority from the detachment of his study, or of a friend of James Pringle whose views were in open contrast with Lind's. Pringle, by the way was loyal to the Hanoverians, whereas it has been suggested that Lind, as a Scot, may have had Jacobite sympathies.

In 1772 Lind published the third edition of his treatise. In a postscript he inserted the substance of four volumes of observations, daily and carefully made on the wards at Haslar Hospital. Just as he had done during his service afloat, Lind had kept records of all his patients: during the first 2 years of his activity at Haslar he saw 1146 cases of scurvy out of 5743 patients (p. 141). During the Seven Years' War (1756-1763) he said he had frequently visited three or four hundred scorbutic patients a day. What use did he make of this unique opportunity?
Lind did not publish lists of his cases, nor numerical results of his therapeutic trials, nor accounts of his autopsies. But there was a change in his theory on scurvy according to his autopsy findings and laboratory experiments with clotted blood, reflecting the "inflammatory nature' of a disease (see [www.jameslindlibrary.org/ trial_records/17th_18th_Century/lind_1762/lind_1762_

Commentary.html]). Lind became reluctant to assert that scurvy was a 'putrid' disease, which he now recognized was an unsatisfactory designation. He had changed his theory of scurvy based on his own observations, a fact worth stressing in view of recently expressed doubts that he practised experimental science. This was important, for it shook the rationale for the therapy with unfermented malt, which had obvious practical and economical advantages: it was easily available, readily stored and cheap. Its main champion was David Macbride, an Irishman who had studied in Edinburgh at the same time as Lind. Unsurprisingly, the Admiralty became interested in it.

Justifying his change of view concerning putrefaction, Lind wrote:

'some doubtful theoretical doctrines remained unaltered, as resting on the faith and dissections of other authors, and as being agreeable to the present theories of physic; . . . but the theory of . . . [scurvy] as well as of many other diseases, is in general merely conjectural, and is always the most exceptional part of a medical performance . . . it is indeed not probable, that a remedy for the scurvy will ever be discovered, from a preconceived hypothesis; or by speculative men in the closet, who have never seen the disease, or . . . at most, only a few cases of it.'

Lind's new clinical experiences were summarized in the postscript, which referred to experiences relating to, for example, 'some thousand', 'several thousand', 'above two thousand', 'some hundreds', or 'ten or twelve out of the number of 100 scorbutic patients'. As to the therapy of scurvy, he inserted letters from four naval surgeons relating a total of 232 patients with the disease who were cured with fruit juices during the Seven Years' War. He said that the wort had not produced 'any considerable effect' in the trials on Wallis's and Carteret's circumnavigations; however, he quoted the testimony of one of Carteret's soldiers who had assured him personally that he had been restored to health by it! In fact, when reporting his own trials, Lind also had a good word for the wort. Macbride's infusion of malt was the only omission from Lind's list of 'all the medicines and methods of cure that have been recommended for this disease' of which he had made it his 'study for some years, with unvaried diligence, to observe the effects by putting them to the fairest trials' (that is, 'scorbutic juices', 
scurvy-grass juice, Peruvian bark in large quantities, infusions of guianac). Nor was the wort dealt with in the main text, but only mentioned in a footnote as follows:

'I put 130 scorbutic patients under a course of it for fourteen days, ... . it has the advantages, when newly made, to be extremely palatable, the patients were very fond of it, and there was not one instance of its occasioning sickness, gripes, or purging. On the whole, it is a very nourishing liquor, well adapted for scorbutic patients' (p. 537-40).

It was a cautious, non-committal statement, but considering Lind's popularity among his naval colleagues in 1772, they might well have interpreted it as evidence in favour of the wort.

Lind's studies of the wort had been controlled. Patients were confined in special wards, strictly watched and 'debarred from eating any green vegetable, fruits or roots whatever, though many of them had not tasted anything of that sort for several months; they were not even permitted to taste the hospital broth'; and their state was monitored daily. Comparative effects of different fruits and vegetables were assessed likewise. These experimental conditions had impressed colleagues working on scurvy, like John Clark, whose work is also included in the James Lind Library. Yet in terms of therapeutic recommendations, Lind at best remained neutral, and at worst acquiesced in the views of the authorities in the Admiralty, who had based their views on confusing reports from circumnavigators like Cook and their surgeons.

Like his counterpart in the Army, John Pringle, Lind was both an experimental scientist and a theoretician working in the speculative framework of his time. But at least Lind undertook the verification of one of his hypotheses. Even with respect to therapy for scurvy, he may have been more objective an observer than sometimes suggested, for many of his scurvy patients probably suffered from a mixed deficiency of both vitamins $B$ and $C$, and wort was rich in vitamin B complex. 'Est modus in rebus, sunt certi denique fines'.

By the time third edition of Lind's treatise appeared, Thomas Cook had already departed on his second voyage (1772-1775), which, in terms of survival from disease, proved to be an even more spectacular success than the first (during a voyage of 70000 miles lasting over 3 years in every variety of climate there were only three deaths from accidents and one from consumption out of a total complement of 118 men). On the basis of the same kind of superficial evidence as on his first voyage, the value of wort was professed in a paper that Cook read at the Royal Society on 7 March 1776. Cook admitted to having been provided with 'rob' of lemons, 'which the surgeon found useful in several cases'. But on 7 July he wrote to Sir John Pringle, then President of the Royal Society, reiterating his low opinion as opposed to the high price of the 'rob' in which he was perhaps not entirely agreed with Cook.

It seems that Cook's and Pringle's inability to discriminate between essential and contributory factors in scurvy delayed the general introduction of lemon juice. The unusually low incidence of scurvy on Cook's ships is rightly attributed to his leadership and his opportunities for obtaining fresh vegetables. Pringle himself thought it probable that the fresh juices had been weakened during evaporation to condensate ('rob'), 'having lost their aqueous parts [and] not a little of their aerial, on which so much of their antiseptic virtue depended'. He proposed further trials with entirely purified juice, because there were 'some numerous and some strong' testimonies in favour of its salutary qualities that a few failures - as in Cook's case-were not sufficient for striking it off the list of probable preservatives against scurvy.

Cook's and Pringle's statements were overwhelming, and internationally recognized. Macbride quickly and proudly quoted them in 1777 as his principal testimonies for the use of malt ('wort') in the Navy and in garrisons. Fairly enough, he gave Lind the entire credit for the prescription of fruit juices and fresh vegetables. Their drawback, however, was that they presupposed favourable circumstances for obtaining them. A change of general opinion was only brought about by the extensive numerical data from the American War of Independence. It had begun in 1774 and was to become widespread by 1778 . The official policy for the prevention of scurvy derived from Cook's recommendations: the Navy Sick and Hurt Board allowed malt ('wort'), sauerkraut and potable soup, whereas the condensate ('rob') of fruit juice was considered ineffective and too expensive. Some naval surgeons, however, looked on it as a medicament that they might occasionally provide from their own purse.

The deliberate use of quantitative methods during the American War yielded a clearer description of the aetiology of scurvy, and, by the mid-1780s, Robertson (1777), Blane (1785), and John Clark had advanced understanding of which treatments were likely to be useful. Clark, in particular, contributed importantly with his blunt numerical evidence suggesting that currently used treatments had been largely ineffective (1783). On the other hand, such observational books, especially if they contained many figures, were sometimes considered a new kind of dull literature, and were despised by many. However, they must have proved more convincing in the long run, even to the authorities, than conjectural arguments of men of the opposition. It was perhaps luck that the 'right' side fought with those better weapons, for, as has been shown repeatedly, statistics can be abused. 
The Admiralty remained unconvinced in the 1780 s that fruit juices were useful, and their final approval by the Navy Sick and Hurt Board was apparently accidental. Part of the story says that in 1793, upon Blane's advice to a friend appointed to East India, a fleet well supplied with lemon juice (preserved with alcohol) reached Madras scurvy-free after 19 weeks without putting in to any port. This remarkable demonstration of the effect of lemon juice enabled Blane, now himself a commissioner on the Board, to persuade the Admiralty in 1795 to sanction the issue of lemon juice on a far more generous scale than ever before. A number of other naval surgeons claimed equal credit for introducing lemon juice in the fleets under their responsibility before a general order was issued. This is perhaps of less concern to us than the fact that the consequences were again easily expressed numerically. For instance, it is said that, when in 1797, the First Lord of the Admiralty asked to see a patient with scurvy when visiting Haslar Hospital, no such patient could be found. In 1815 Gilbert Blane showed that the scurvy had almost disappeared from the fleet: according to the figures sent to him by Dr John Lind, the son and successor of James at Haslar, only two cases had been sent to the Hospital during the last 4 years of the Napoleonic Wars.

In summary, the history of scurvy in the British Navy during the second half of the 18th century shows how comparative clinical trials in controlled conditions of time and environment were well described by Lind, yet, initially for understandable reasons, imperfectly translated into practice, and only on a very small scale. The pathophysiological explanation of scurvy remained speculative, at least in its earlier decades, thus not avoiding the episode of Macbride's malt ('wort'). Due to the interplay of accurate observation and simple numerical records from individual ships and whole fleets in wartime kept by Robertson and Blane, however, both the clinical features of scurvy and the effects of preventive and therapeutic strategies became better assessed. This led ultimately to a change of professional and political opinion in favour of lemon juice among the authorities directing the naval service, and thus to the conquest of scurvy.

Acknowledgments This paper was previously published by The James Lind Library [www.jameslindlibrary.org]. Accessed 28 September 2005.

\section{REFERENCES}

1 Lind James. A Treatise of the Scurvy in Three Parts. Containing an Inquiry into the Nature, Causes and Cure of that Disease, together with a Critical and Chronological View of what has been published on the subject. London: Miller, 1753

2 Tröhler U. Quantification in British Medicine and Surgery 1750-1830, with Special Reference to its Introduction into Therapeutics [PhD Thesis]. London: University of London, 1978:346-96

3 Tröhler U. 'To improve the evidence of medicine. The 18th century British origins of a critical approach.' Edinburgh: Royal College of Physicians, 2000:59-68

4 Tröhler U. Towards clinical research on a numerical basis: James Lind at Haslar Hospital 1758-1783. Proceedings of the XXVII International Congress History of Medicine Barcelona, 1980. Barcelona: Academia de Ciènces Mediques de Catalunya I Balears 1, 1981:414-419 